\title{
Klaus Herbers, Europa: Christen und Muslime in Kontakt und Konfrontation. Italien und Spanien im langen 9. Jahrhundert
}

Fernand Peloux

\section{OpenEdition}

Édition électronique

URL : http://journals.openedition.org/ifha/8878

DOI : $10.4000 /$ ifha. 8878

ISSN : 2198-8943

\section{Éditeur}

IFRA - Institut franco-allemand (sciences historiques et sociales)

\section{Référence électronique}

Fernand Peloux, « Klaus Herbers, Europa: Christen und Muslime in Kontakt und Konfrontation. Italien und Spanien im langen 9. Jahrhundert », Revue de l'IFHA [En ligne], Date de recension, mis en ligne le 02 novembre 2017, consulté le 23 septembre 2020. URL : http://journals.openedition.org/ifha/8878 DOI : https://doi.org/10.4000/ifha.8878

Ce document a été généré automatiquement le 23 septembre 2020.

(CIFHA 
Klaus Herbers, Europa: Christen und Muslime in Kontakt und Konfrontation. Italien und Spanien im langen 9. Jahrhundert

Fernand Peloux

\section{RÉFÉRENCE}

Klaus Herbers, Europa: Christen und Muslime in Kontakt und Konfrontation. Italien und Spanien im langen 9. Jahrhundert, Stuttgart: Franz Steiner Verlag, 2016, 112 p., $18 €$ 
Ce livre est à la fois un essai et une synthèse des précédents travaux de recherche de Klaus Herbers. De manière claire et nuancée, l'auteur réussit à traiter en peu de pages un sujet ambitieux tout autant qu'historiographiquement chargé, voire polémique. Il procède à l'analyse comparée des relations francomusulmanes en Espagne et en Italie du Sud dans ce qu'il appelle "un long $\mathrm{IX}^{\mathrm{e}}$ siècle ». L'auteur part de la trop célèbre victoire de Charles Martel sur Abd alRahman près de Poitiers en 732 , pour interroger l'idée d'une Europe chrétienne et ses relations avec l'Islam: violence, échanges, confrontation et/ou relations transculturelles? Dans une telle perspective, et au bout d'une chaîne historiographique parfois pesante, au commencement de laquelle on trouve Henri Pirenne, il examine ces deux espaces de contacts après avoir rapidement rappelé les principales sources et la chronologie des principales avancées territoriales, musulmanes ou chrétiennes.

K. Herbers commence par examiner la situation du point de vue chrétien avec les Carolingiens, à commencer par Charlemagne, dont l'expédition de 778 qui a conduit à la défaite de Roncevaux est alors présentée comme défensive. Sous le règne de Louis le Pieux, alors qu'on trouve de nombreux hispani dans le sud de la France, la lettre de l'Empereur aux chrétiens de Mérida n'est nullement rédigée dans une perspective religieuse. Ensuite l'auteur déplace la focale du côté de la papauté et de la péninsule italienne où la domination territoriale des Musulmans est bien moindre mais où la confrontation est certaine, et où les travaux de construction comme la liturgie ainsi que la figure de saint Paul sont utilisés comme des armes, notamment sous le pontificat de Jean VIII. Une lettre de ce dernier, de même que différents documents produits par la papauté au IX ${ }^{\mathrm{e}}$ siècle, est ensuite utilisée à partir de la fin du $\mathrm{XI}^{\mathrm{e}}$ siècle pour fonder idéologiquement la croisade. En même temps, les échanges sont intenses : ils peuvent être financiers et commerciaux (esclaves, papyrus).

Du point de vue des différents acteurs d'une Italie méridionale multiple, la situation est complexe, les villes d'Amalfi, de Naples et de Gaeta s'étant alliées aux musulmans contre l'avis de la papauté. De même, les empereurs d'Occident Louis II et d'Orient Basile $\mathrm{I}^{\mathrm{er}}$ sont en concurrence, comme le montre l'analyse de la prise de l'émirat de Bari par les Francs en 871. Dans les sources du Mont-Cassin, les musulmans et les Grecs sont traités négativement à égalité. Dans l'espace sicilien, la lettre du moine Théodose à l'archidiacre Léon au moment de la prise de la ville en 878 souligne la diversité des populations lors de sa captivité. Dans la péninsule ibérique, c'est après l'invasion de 711 que l'Hispania naît dans l'historiographie du Nord du royaume, et après l'érection de l'Émirat à Cordoue en 756, les musulmans travaillent à l'unité dans un espace en voie d'arabisation où cohabitent divers groupes, dont les Mozarabes. Au milieu du IX ${ }^{\mathrm{e}}$ siècle, 
l'épisode des martyrs de Cordoue, en partie calqué sur des modèles de sainteté tardoantique, est un cas riche et extrême de confrontation religieuse : la lettre d'Euloge de Cordoue à l'évêque Wilisinde de Pampelune témoigne de la circulation des chrétiens et du rôle intellectuel des monastères pyrénéens en même temps qu'il fonde le culte liturgique des martyrs de sa ville. La question de la langue, non négligeable, n'est pas superposable aux tensions religieuses : elle est aussi au cœur des difficultés en dépit des efforts de traduction et des échanges qui supposent des circulations de reliques et des migrations. L'auteur poursuit son analyse de la situation hispanique par un examen des sources littéraires, en particulier des chroniques asturiennes en étudiant la manière dont elles traitent des batailles de Guadalete (711) et de Covadonga (722 ?). Cela permet de constater la différence des interprétations selon les milieux dans lesquels les sources sont produites.

Si les relations entre les Carolingiens et la péninsule ibérique se caractérisent par une relative ignorance, la situation est plus complexe dans le cas italien du fait de la situation politique et du discours à la fois religieux et juridique de l'évêque de Rome. Les sources pontificales vont plus loin dans la désignation du Sarrasin en ennemi d'une patrie qu'il faut défendre. Cette patria apparaît bien différente de celle que les sources du nord de l'Espagne appellent à restaurer après sa perte, au moment où se met en place, selon l'auteur, une mythologie collective qui s'appuie sur les batailles de Guadalete et de Covadonga comme lieux de mémoire fondateurs d'une identité.

Ce livre, aussi bref qu'efficace, est un essai d'histoire globale qui n'abandonne jamais la rigueur de l'argumentation en renvoyant toujours avec précaution aux sources. Il invite constamment à interroger les différents points de vue et les représentations réciproques afin de restituer toute la complexité de ce long IX ${ }^{\mathrm{e}}$ siècle.

INDEX

Index chronologique : Moyen Âge

Thèmes : Histoire religieuse ; Histoire sociale

\section{AUTEURS}

FERNAND PELOUX

UNamur 